\title{
Etude sur la technique de préparation de la présure utilisée dans les fabrications traditionnelles des fromages de gruyère de Comté et d'Emmental
}

\author{
par \\ E. VALLES et G. MOCQUOT
}

(avec la collaboration technique de Lynne FORSTER et J.P. FURET) Station Centrdle de Recherches Laitières et de Technologie des Produits Animaux, C.N.R.Z., I.N.R.A. (78) Jouy-en-Josas

\section{INTRODUCTION}

Dans les fromageries de la zone d'origine du gruyère, la présure est préparée par les fromagers eux-mêmes. Ce mode de préparation artisanal se maintient encore de nos jours dans la presque totalité des fromageries de la Franche-Comté.

Il procure en effet au fromager un moyen de coaguler son lait d'une part et, d'autre part, de l'ensemencer avec certaines bactéries lactiques thermophiles : la présure artisanale est à la fois un levain et une présure. La préparation s'obtient en faisant macérer les caillettes de veau soit dans du lactosérum, - dans lequel se développent à la fois les streptocoques thermophiles et les lactobacilles - soit dans la " recuite » (c'est-à-dire du lactosérum désalbuminé par chauffage et acidification) favorable, en raison du bas $\mathrm{pH}$, au développement des seuls lactobacilles. De plus, au cours de la macération et de l'acidification on observe que l'enzyme coagulant, la présure, est extrait des caillettes de veau.

Parmi les nombreuses publications sur la bactériologie de ces présures artisanales et des fromages à pâte cuite, certaines [1 à 9] montrent que les bactéries lactiques thermophiles nécessaires à l'acidification de la pâte des fromages sous presse, appartiennent aux genres Lactobacillus (notamment $L$. lactis, L. helveticus, L. bulgaricus) et Streptococcus (Str. thermophilus).

La description de divers modes de préparation de ces présures artisanales et des levains utilisés dans les fabrications des fromages 
de Gruyère et d'Emmental a été donnée par Peter et al. [10] ; Dorner et al. [11] ; Kursteiner et Staub [12].

La présure sur lactosérum, utilisée avec succès en Suisse, n'a pas donné de bons résultats en France en ce sens qu'elle ne conduit pas d'une façon sûre et pratique à maintenir l'équilibre désirable entre les lactobacilles et les streptocoques thermophiles. Des facteurs tels que la composition du milieu de culture, le $\mathrm{pH}$, la température et les durées d'incubation, la présence de bactéries indésirables, etc., ne sont pas facilement contrôlables par le fromager.

Malgré ces difficultés, une chose est certaine : les différents types de présures artisanales sont encore conservés par les fromagers, alors que l'emploi de la présure commerciale et d'une culture séparée de ferments lactiques demeure assez limité.

L'attachement des fromagers à leurs présures artisanales résulte peut-être du fait qu'ils peuvent ainsi disposer d'une façon relativement simple à la fois d'un levain et de la présure. Mais un autre élément, qui semble avoir contribué au maintien du procédé traditionnel, est l'opinion assez répandue dans le métier que, parmi les beaux fromages, les meilleurs, au point de vue goût et finesse d'arôme et de pâte, sont ceux qui ont été fabriqués avec des présures artisanales bien réussies. Autrement dit, ces présures artisanales renfermeraient sous une forme ou une autre, une grande partie des éléments responsables d'une qualité supérieure du fromage.

Il faut mentionner d'ailleurs que plusieurs auteurs ont établi des différences entre les fromages fabriqués avec ces présures et la présure commerciale $[13,14,15]$.

Certes, il a été maintes fois reconnu qu'un très grand nombre de fromages de second et troisième choix présentaient des défauts se rapportant à l'emploi de présures artisanales, elles-mêmes défectueuses. Il est également admis d'autre part qu'il n'est pas toujours facile d'obtenir des présures artisanales possédant une qualité constante. En outre, il s'avère parfois difficile de bien régler le peuplement du lait en bactéries lactiques thermophiles tout en ajoutant la quantité optimum de présure.

Il faut aujourd'hui considérer également un autre aspect du problème : à l'heure actuelle, l'utilisation des présures artisanales dans les fabrications traditionnelles de fromages de Comté et d'Emmental se heurte à la pénurie mondiale de caillettes de veau. On peut se demander si cette méthode artisanale de préparation de la présure ne comporte pas un gaspillage d'une matière première précieuse susceptible de devenir de plus en plus rare.

Le but du présent travail est d'étudier comment se fait l'extraction de la présure (et de la pro-présure avec activation de ce proenzyme), lors de l'emploi de la technique de préparation des présures artisanales à partir de caillettes de veau sèches. 


\section{MATERIEL ET METHODES}

\section{A) Préparation des présures dites " naturelles "}

Parmi les différents procédés de préparation des présures de fromagerie on a retenu, pour l'étude de l'extraction de la présure, celui qui comporte l'acidification des milieux de macération grâce aux seuls lactobacilles. Ce procédé fait partie, dans ses grandes lignes, du procédé utilisé depuis 1969 dans plusieurs fromageries du Jura*, et comportant l'emploi d'une présure à la « recuite » inoculée avec $L$. helveticus et d'une culture séparée de Str. thermophilus (préparée en inoculant cette bactérie dans un milieu de culture constitué par le mélange de quatre parties de lactosérum frais et d'une partie de lait écrémé) et en incubant la présure à la « recuite » et la culture de Str. thermophilus à $42^{\circ} \mathrm{C}$.

\section{1) Caillettes}

Les caillettes sèches employées étaient livrées par lots de douze caillettes. Avant utilisation on les découpait une à une en lanières en partant de chaque extrémité de la caillette et en allant vers le centre jusqu'à l'obtention d'un poids déterminé permettant de réaliser un nombre suffisant d'essais. Les lanières ainsi obtenues étaient bien mélangées, découpées finement, puis mélangées à nouveau. Le tout était enfermé dans un bocal en verre jaune maintenu à température ambiante $\left(20\right.$ à $\left.25^{\circ} \mathrm{C}\right)$. Avant de procéder à chaque essai, une portion des caillettes découpées était retirée du bocal, mélangée à nouveau et on prélevait sur cette portion le poids nécessaire pour l'essai considéré.

\section{2) MilieuX DE MacÉRATION}

\section{Lactosérum de fromagerie}

Le lactosérum, dont le $\mathrm{pH}$ était compris entre 6,45 et 6,50 , était prélevé au cours d'une fabrication de Gruyère (aussitôt après que le fromage ait été retiré de la cuve) et porté en $6 \mathrm{mn}$ environ à une température comprise entre 75 et $78^{\circ} \mathrm{C}$. Il était maintenu à cette température pendant $5 \mathrm{mn}$. Ensuite il était refroidi en 4 à $6 \mathrm{mn}$ environ à la température de macération, $42^{\circ} \mathrm{C}$.

\section{"Recuite "}

Le lactosérum de fromagerie prélevé au même stade que le précédent était chauffé à une température comprise entre 93 et $95^{\circ} \mathrm{C}$ en agitant continuellement. Une fois cette température atteinte on

\footnotetext{
* Action " pilote » entreprise dans le cadre du Comité Interprofessionnel du Gruyère de Comté (1969-1972).
} 
versait une quantité convenable (environ $40 \mathrm{ml}$ pour $1 \mathrm{l}$ de lactosérum) d'une solution à $20 \mathrm{~g}$ d'acide lactique par litre, de façon à précipiter les protéines solubles et à obtenir ensuite un liquide clair, la " recuite ", dont l'acidité était comprise entre 16 et $17^{\circ} \mathrm{D}(0,16$ $0,17 \mathrm{~g}$ d'acide lactique pour $100 \mathrm{~g}$ de lactosérum) et le $\mathrm{pH}$ compris entre 5,20 et 5,40 . Une fois la solution d'acide lactique ajoutée, la température était portée à 97 ou $98^{\circ} \mathrm{C}$, puis le chauffage et l'agitation étaient arrêtés. Après 3 à $5 \mathrm{mn}$, on enlevait avec une écumoire le précipité formé en surface et la "recuite " était refroidie à la température de macération, en général $42^{\circ} \mathrm{C}$ (ceci est précisé à propos de chaque essai).

\section{3) PRÉPARATION des MACÉRATIONS}

La macération dans la « recuite » ou dans le lactosérum était préparée selon les techniques suivantes :

a) Méthode "traditionnelle »

Cette méthode comporte l'addition des caillettes et l'ensemencement simultané avec les bactéries lactiques. Dans des flacons en verre Pyrex de capacité variable (1 à 5 1), le lactosérum ou la " recuite " étaient inoculés avec une culture de L. helveticus* à la dose de 1 p. 100 ou avec une suspension concentrée et congelée du même germe [16] à la dose de 0,1 p. 100 .

La quantité nécessaire de caillettes était alors ajoutée et les flacons étaient incubés au bain-marie à la température choisie (à $\pm 0,5^{\circ} \mathrm{C}$ près). La durée d'incubation était de 8 à $10 \mathrm{~h}$ pour les macérations faites à $42^{\circ} \mathrm{C}$ et de 24 à $28 \mathrm{~h}$ pour les macérations effectuées à $30^{\circ} \mathrm{C}$. Dans le premier cas, une fois l'incubation terminée, les flacons étaient sortis du bain-marie et, selon la pratique couramment utilisée en fromagerie, ils étaient placés à une température comprise entre 20 et $25^{\circ} \mathrm{C}$ pendant 12 à $14 \mathrm{~h}$. D'autres conditions de macération qui ont été également utilisées sont précisées lorsque c'est nécessaire.

\section{b) Méthode "à $p H$ constant»}

Dans le procédé qui vient d'être décrit, les bactéries lactiques se développent et la macération s'acidifie progressivement au cours de l'incubation. On a aussi étudié l'obtention de présure dans des macérations à " $\mathrm{pH}$ constant " ainsi préparées : le $\mathrm{pH}$ de la "recuite " ou du lactosérum était ajusté au préalable à une valeur déterminée par addition d'acide lactique pur ou par acidification au moyen d'une culture de bactéries lacticues thermophiles. Dans le deuxième cas, la « recuite », ou le lactosérum étaient inoculés comme nous l'avons décrit dans la méthode traditionnelle et ils étaient incubés jusqu'au terme de l'acidification (c'est-à-dire pen-

* Culture sur lait stérilisé par autoclavage, incubée pendant 6 à 8 h à $42^{\circ} \mathrm{C}$. 
dant 14 à $16 \mathrm{~h}$ à $42^{\circ} \mathrm{C}$ ). Dans ces conditions le $\mathrm{pH}$ de la « recuite » ou du lactosérum était compris entre 3,4 et 3,8 . C'est dans ces milieux déjà acides que les caillettes étaient alors ajoutées et mises à macérer.

\section{B) Bactéries lactiques}

Nous avons utilisé les souches de L. helveticus 303 et 32 de la collection du C.N.R.Z.

\section{C) Détermination de la concentration en présure}

On suivait la technique et le mode d'expression des résultats décrits par Berridge [17]. Les modifications suivantes ont été apportées à la technique originale.

\section{a) Lait en poudre utilisé}

$\mathrm{Au}$ lieu d'utiliser un lait n'ayant subi qu'un préchauffage modéré comme le recommande l'auteur, on a employé un lait écrémé en poudre instantané, vendu dans le commerce sous la dénomination de "lait sec granulé "*. Ce lait, du fait du traitement thermique subi et du traitement destiné à le rendre soluble, était vraisemblablement un peu différent du lait utilisé par Berridge.

\section{b) Préparation du substrat}

Le lait était reconstitué en ajoutant $120 \mathrm{~g}$ de poudre à 11 de $\mathrm{CaCl}_{2} 0,01 \mathrm{M}$. La poudre était versée à la surface de la solution contenue dans un bécher et elle était mélangée à l'aide d'un agitateur magnétique pendant $15 \mathrm{mn}$. Le lait ainsi obtenu était réparti, à raison de $10 \mathrm{ml}$, en tubes à essai $(18 \times 180)$ et conservé à température ambiante $\left(20\right.$ à $\left.25^{\circ} \mathrm{C}\right)$. Il était utilisé au cours des $10 \mathrm{~h}$ suivant sa préparation. Le $\mathrm{pH}$ de ce substrat était compris entre 6,22 et 6,26.

c) Dilution des échantillons et ajustement $d u p H$.

Les échantillons de présure étaient dilués afin d'obtenir des temps de coagulation compris entre 4 et $10 \mathrm{mn}$ pour un $\mathrm{pH}$ du mélange réactionnel ( $1 \mathrm{ml}$ de présure diluée $+10 \mathrm{ml}$ de substrat) compris entre 6,22 et 6,26 .

Des temps de coagulation compris entre 4 et $10 \mathrm{mn}$ étaient obtenus sans difficulté en diluant certains échantillons avec de l'eau distillée. Toutefois avec ce diluant, l'ajustement du $\mathrm{pH}$ du mélange réactionnel était assez délicat. Dans le cas de présures faibles (1 à 10 unités-présure par $\mathrm{ml}$ ) et très acides ( $\mathrm{pH}$ compris entre 3,0 et 2,0), les dilutions permettant l'obtention des temps de coagulation indiqués ne donnaient pas le $\mathrm{pH}$ convenable. Pour surmonter cette

* Ce lait est fabriqué par I’Union Laitière Normande à Condé-sur-Vire (50). 


\section{TABLEAU 1}

Dilutions des présures liquides en fonction du $\mathrm{pH}$ pour l'obtention de temps de coagulation compris entre 4 et $10 \mathrm{mn}$

\begin{tabular}{|c|c|c|c|c|c|}
\hline Présures & Force* & $\begin{array}{l}\text { Dilution } \\
\text { au }\end{array}$ & Diluant & $\begin{array}{l}\mathrm{pH} \text { de la } \\
\text { dilution }\end{array}$ & $\begin{array}{l}\mathrm{pH} \text { du mélange } \\
\text { réactionnel }\end{array}$ \\
\hline $\begin{array}{l}\mathrm{pH} \\
2,0\end{array}$ & $\begin{array}{r}1 \text { à } \\
4 \text { à } \\
10 \\
10 \text { à } 20 \\
20 \text { à } 40 \\
40 \text { à } 100\end{array}$ & $\begin{array}{l}1 / 10 \\
1 / 25 \\
1 / 50 \\
1 / 100 \\
1 / 250\end{array}$ & $\begin{array}{l}\text { Véronal } 0,108 \mathrm{M} \\
\text { Véronal } 0,04 \mathrm{M} \\
\text { Véronal } 0,02 \mathrm{M} \\
\text { Véronal } 0,01 \mathrm{M} \\
\text { Eau distillée }\end{array}$ & $\begin{array}{l}5,64 \\
5,46 \\
5,84 \\
3,90\end{array}$ & $\begin{array}{l}6,26 \\
6,24 \\
6,26 \\
6,24 \\
6,26\end{array}$ \\
\hline 2,5 & $\begin{array}{rr}1 \text { à } & 4 \\
4 \text { à } & 10 \\
10 \text { à } & 20 \\
20 \text { à } 100\end{array}$ & $\begin{array}{c}1 / 10 \\
1 / 25 \\
1 / 50 \\
1 / 100-1 / 250\end{array}$ & $\begin{array}{c}\text { Véronal } 0,025 \mathrm{M} \\
\text { Véronal } 0,01 \mathrm{M} \\
\text { Acétate Na } 0,05 \mathrm{M} \mathrm{pH} 6,7 \\
\text { Eau distillée }\end{array}$ & $\begin{array}{l}4,20 \\
4,26 \\
5,3 \\
3,0\end{array}$ & $\begin{array}{l}6,22 \\
6,26 \\
6,26 \\
6,24\end{array}$ \\
\hline 3,0 & $\begin{array}{rr}1 \text { à } & 4 \\
4 \text { à } & 10 \\
10 & \text { à } 100\end{array}$ & $\begin{array}{c}1 / 10 \\
1 / 25 \\
1 / 50-1 / 250\end{array}$ & $\begin{array}{l}\text { Véronal } 0,01 \mathrm{M} \\
\text { Acétate Na 0,05 M pH 6,7 } \\
\text { Eau distillée }\end{array}$ & $\begin{array}{c}4,0 \\
4,5 \\
3,4-4,8\end{array}$ & $\begin{array}{c}6,24 \\
6,22 \\
6,24-6,26\end{array}$ \\
\hline \multirow[t]{2}{*}{3,5 à 6,0} & 1 à 4 & $1 / 10$ & Acétate $\mathrm{Na} 0,05 \mathrm{M} \mathrm{pH} 6,7$ & 4,9 & $6,22-6,26$ \\
\hline & 4 à 100 & $1 / 25-1 / 250$ & Eau distillée & $3,6-6,6$ & $6,24-6,26$ \\
\hline
\end{tabular}

* Unités-présure par ml (ou par g). 
difficulté, nous avons essayé d'autres diluants permettant d'obtenir dans le mélange réactionnel (présure + substrat) un $\mathrm{pH}$ compris entre 6,22 et 6,26 et nous avons retenu les suivants :

Solution d'acétate de sodium $0,05 \mathrm{M}, \mathrm{pH}$ 6,7 : cette solution était préparée à partir d'une solution d'acétate de sodium $0,2 \mathrm{M}$, ajustée à $\mathrm{pH} 6,7$ avec de l'acide acétique $0,2 \mathrm{M}$ et amenée au volume avec de l'eau distillée.

Des essais préliminaires ont montré que la solution d'acétate de sodium $0,05 \mathrm{M}, \mathrm{pH}$ 6,7 donnait (à conditions égales de $\mathrm{pH}$ dans le mélange réactionnel) des résultats du même ordre que ceux obtenus avec l'eau distillée.

Solutions de véronal sodique : $0,108 \mathrm{M}, 0,040 \mathrm{M}, 0,020 \mathrm{M}, 0,025 \mathrm{M}$ et $0,010 \mathrm{M}$.

Dans les mêmes conditions de $\mathrm{pH}$ du mélange réactionnel, les solutions de véronal sodique utilisées donnaient des temps de coagulation supérieurs de 11 à 15 p. 100 à ceux obtenus avec l'eau distillée.

Néanmoins, l'emploi de ces diluants était justifié dans le cas des présures à $\mathrm{pH} 2,0$ et 2,5 car avec l'eau distillée les $\mathrm{pH}$ étaient respectivement de 5,80 et 6,08 au lieu de 6,24. Dans ces conditions, les temps de coagulation obtenus avec les $\mathrm{pH} 5,80$ et 6,08 , étaient inférieurs respectivement de 70 et 25 p. 100 à celui obtenu à pH 6,24.

Le tableau 1 montre les différentes conditions de dilution et, à titre indicatif, quelques résultats concernant les $\mathrm{pH}$ des mélanges réactionnels et les $\mathrm{pH}$ des dilutions pratiquées (mélange : présure + diluant).

\section{d) Détermination du temps de coagulation}

Les tubes contenant $10 \mathrm{ml}$ de substrat étaient d'abord portés à $30^{\circ} \mathrm{C} \pm 0,5^{\circ} \mathrm{C}$ par séjour de $10 \mathrm{mn}$ dans un bain-marie réglé à cette température. Ils étaient ensuite utilisés dans les $30 \mathrm{mn}$ suivantes pour la détermination du temps de coagulation à cette même température.

\section{D) Détermination du $\mathrm{pH}$}

Toutes les déterminations de $\mathrm{pH}$ ont été effectuées à $20^{\circ} \mathrm{C}$ avec un pH-mètre Metrohm, modèle E $353 \mathrm{~B}$, avec une électrode de verre permettant la lecture à 0,02 unité $\mathrm{pH}$ près.

\section{E) Conservation des présures}

Les macérations étaient réparties $(10 \mathrm{ml})$ dans des flacons bouchés et placés soit au réfrigérateur entre 3 et $5^{\circ} \mathrm{C}$, soit au congélateur entre $-28^{\circ} \mathrm{C}$ et $-30^{\circ} \mathrm{C}$. 


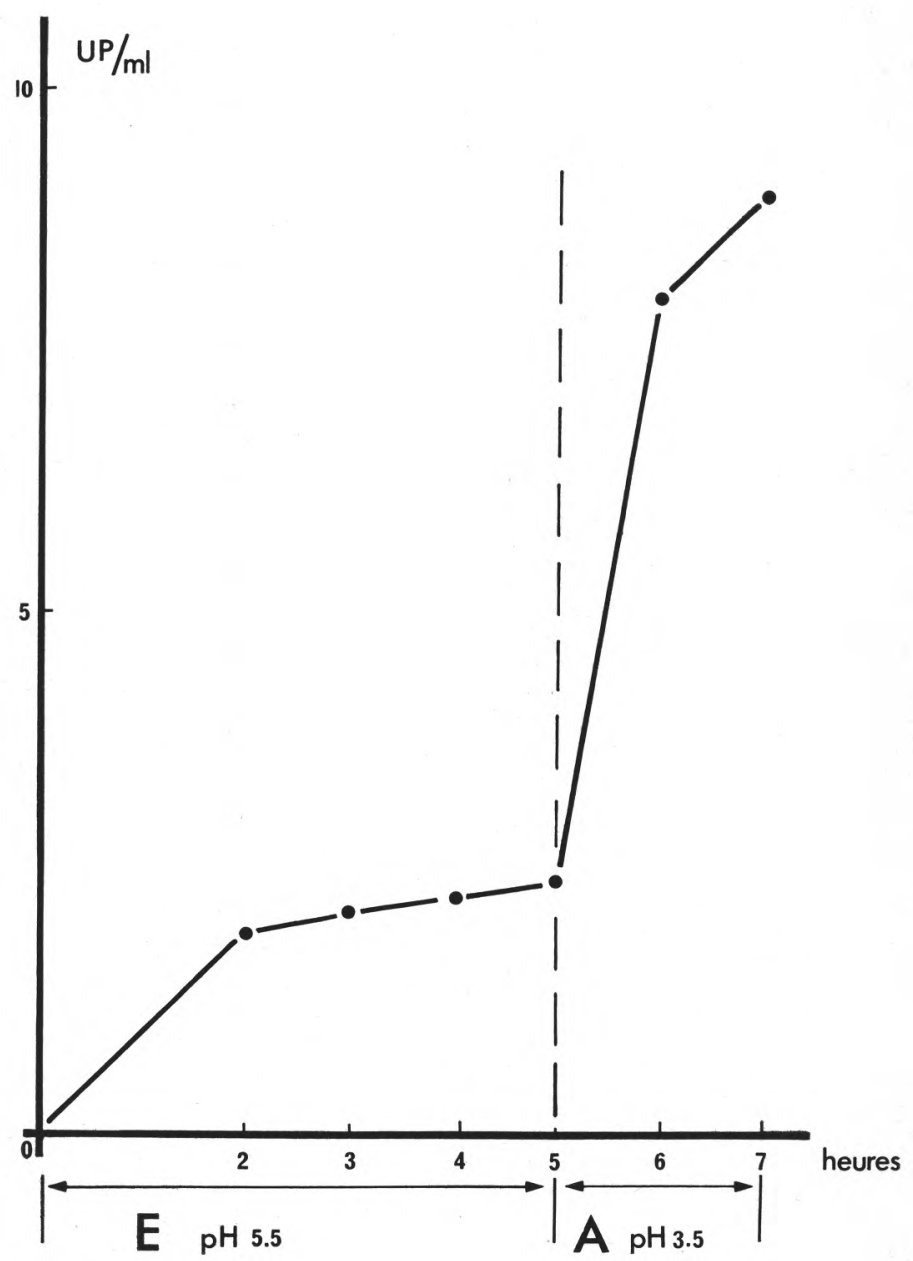

fig 1

Extraction de la présure et de la pro-présure et activation de la pro-présure

Caillettes : $20 \mathrm{~g}+1 \mathrm{I}$ de "recuite » $+1 \mathrm{ml}$ toluène.

Température : $42^{\circ} \mathrm{C}$.

(E) : période d'extraction à $\mathrm{pH}$ constant 5,5.

(A): période d'activation de la pro-présure $(\mathrm{pH} 3,5)$. 
Elles étaient également réparties sur les plateaux du lyophilisateur à raison de $500 \mathrm{ml}$ par plateau (épaisseur de la couche $1 \mathrm{~cm}$ environ). Elles étaient alors congelées entre $-28^{\circ} \mathrm{C}$ et $-30^{\circ} \mathrm{C}$, puis lyophilisées à $20^{\circ} \mathrm{C}$.

Le produit obtenu après lyophilisation était aussitôt broyé dans un mortier, réparti dans des flacons en verre jaune et conservé au réfrigérateur entre $3^{\circ} \mathrm{C}$ et $5^{\circ} \mathrm{C}$.

\section{RESULTATS}

Dans les conditions de préparation des présures artisanales telles qu'elles viennent d'être indiquées, on assiste au cours de la macéra-

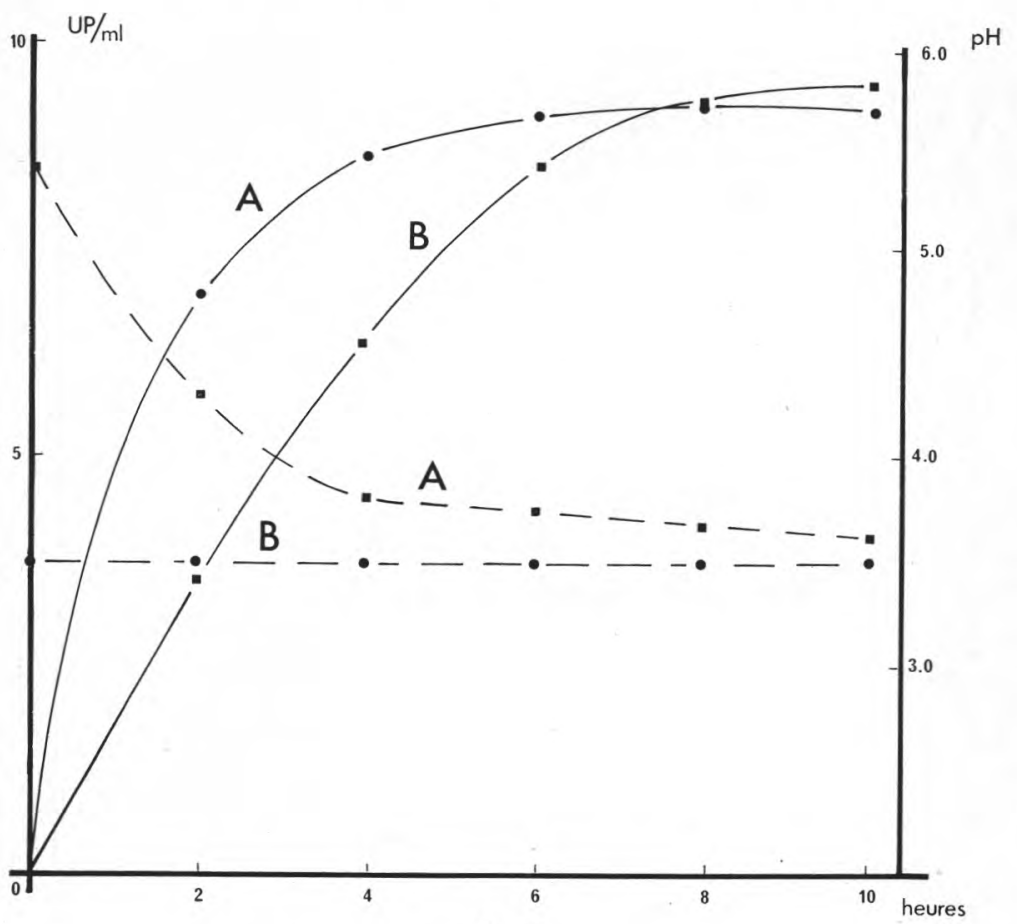

fig. 2

Préparation de présure artisanale

Variation de la concentration en présure. Macérations à $42^{\circ} \mathrm{C}$

A) Méthode "traditionnelle »:

$10 \mathrm{~g}$ de caillettes +11 de "recuite"

$+0,1$ p. 100 de suspension concentrée et congelée de L. helveticus.

B) Méthode "à pH constant ":

$10 \mathrm{~g}$ de caillettes +11 de "recuite " acidifiée à $\mathrm{pH}$ 3,4.

\begin{tabular}{ll} 
& $\mathrm{UP} / \mathrm{ml}$ \\
\hdashline$-\backsim-\backsim$ & $\mathrm{pH}$
\end{tabular} 
tion à l'extraction de la présure et de la pro-présure et à l'activation du pro-enzyme.

Dans la plupart des cas, on mentionne dans ce qui suit «l'action globale " résultant de l'ensemble de ces deux processus. Cependant, à titre indicatif, on a montré dans un essai l'extraction de la présure et de la pro-présure et l'activation de la pro-présure : $10 \mathrm{~g}$ de caillettes sont mis à macérer à $\mathrm{pH} 5,5$ dans $1 \mathrm{l}$ de " recuite » auquel on a ajouté $1 \mathrm{ml}$ de toluène. La présence de toluène empêche la croissance des bactéries lactiques éventuellement apportées par les caillettes. La macération à $\mathrm{pH}$ constant est poursuivie jusqu'à ce que la concentration en présure n'augmente plus de manière sensible. Les caillettes sont alors retirées, le $\mathrm{pH}$ est ajusté à 3,5 par addition d'acide lactique pur et l'incubation est poursuivie à $42^{\circ} \mathrm{C}$. L'augmen-

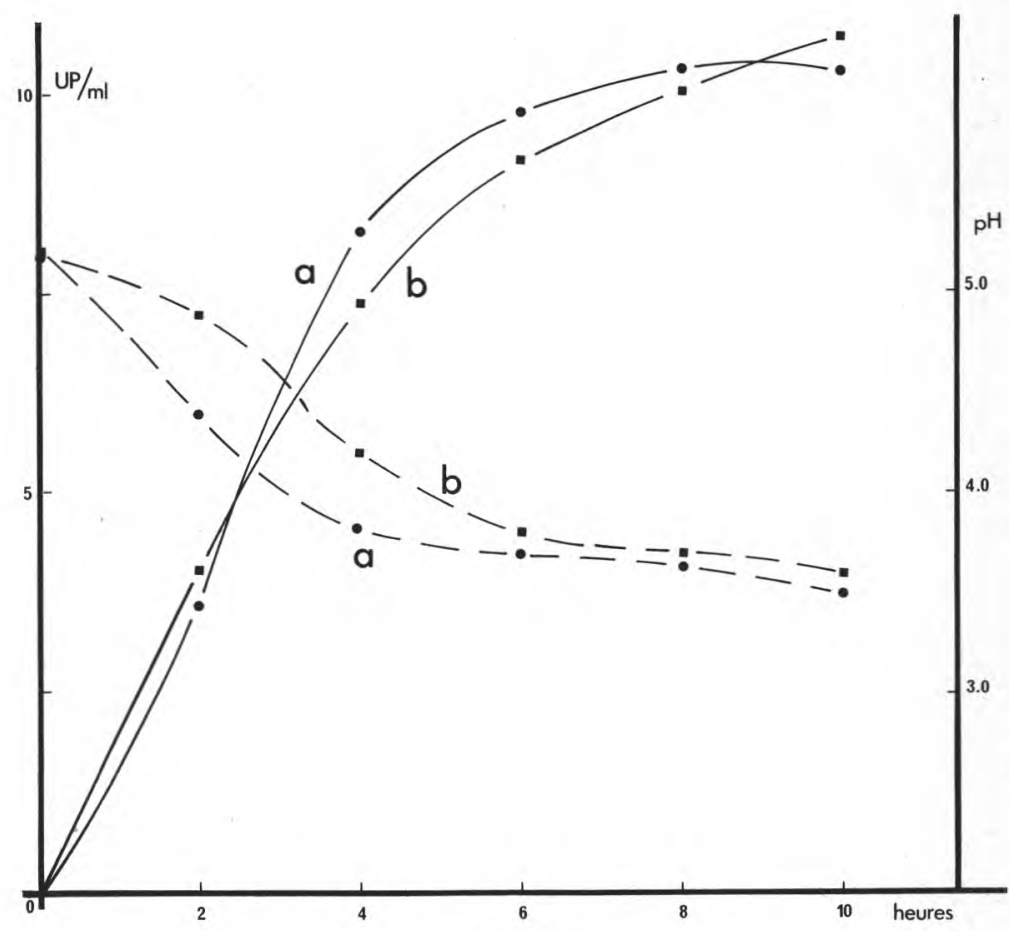

fig. 3

Variation de la concentration en présure Méthode "traditionnelle ": $10 \mathrm{~g}$ de caillette $+11 \mathrm{de}$ "recuite ». Température $45^{\circ} \mathrm{C}$.

a) $+0,1$ p. 100 de suspension concentrée et congelée de L. helveticus.

b) +1 p. 100 de culture sur lait autoclavé de $L$. helveticus.

$\mathrm{UP} / \mathrm{ml}$.

$\mathrm{pH}$. 
tation de la concentration en présence observée montre clairement le phénomène d'activation de la pro-présure (fig. 1).

L'obtention de la présure au cours de la macération de caillettes est conditionnée notamment par le $\mathrm{pH}$ et la température, les rendements d'extraction dépendent en outre de la qualité des caillettes utilisées.

\section{1) INFLUENCE $\mathrm{DU} \mathrm{pH}$}

La figure 2 montre: a) la courbe moyenne d'extraction de la présure et d'évolution du $\mathrm{pH}$ au cours de la macération des caillettes dans la « recuite » selon la méthode «traditionnelle ». b) l'extraction de la présure selon la méthode à " $\mathrm{pH}$ constant » dans la zone 3,8 à 3,4 .

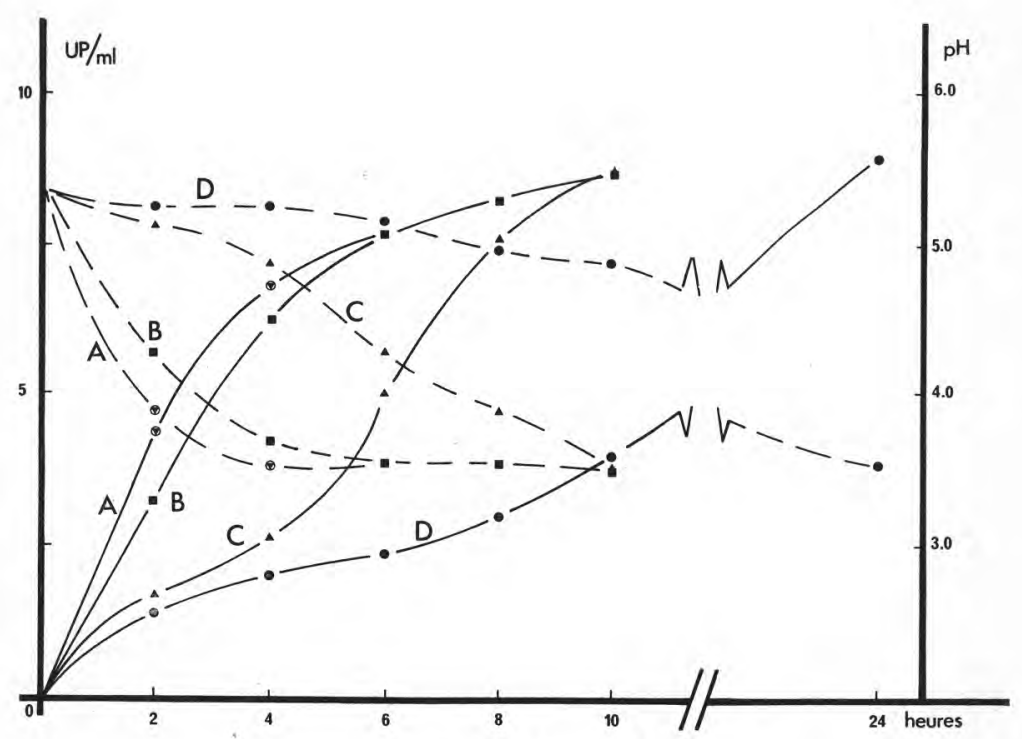

fig. 4

Variation de la concentration en présure au cours des macérations à $42^{\circ} \mathrm{C}$ en fonction de la vitesse d'acidification

Méthode traditionnelle : $10 \mathrm{~g}$ de caillettes +11 de "recuite ".
A) : $\quad+1$ p. 100 de suspension concentrée et congelée de $L$. helveticus.
B) : $\quad+0,1$ p. 100 de suspension concentrée et congelée de L. helveticus.
C) : + 1 p. 100 d'une culture sur lait autoclavé de L. helveticus maintenue à l'étuve pendant $24 \mathrm{~h}$ à $42^{\circ} \mathrm{C}$, au lieu de la durée normale d'incubation ( 6 à $8 \mathrm{~h}$ ).
D) : sans inoculation de L. helveticus (l'acidification est produite par les bactéries apportées par les caillettes).

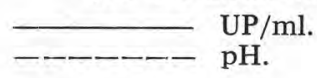


Dans la méthode "traditionnelle ", l'utilisation de suspensions concentrées et congelées de bactéries lactiques thermophiles conduisait aux mêmes résultats que l'emploi de cultures de ces mêmes bactéries sur lait autoclavé, comme le montre la figure 3 .

La figure 4 rend compte des résultats obtenus lors des macérations faites selon la méthode " traditionnelle ", à différentes vitesses d'acidification : plus l'acidification est rapide, plus l'extraction de la présure et l'activation de la pro-présure sont elles-mêmes rapides ; la force coagulante maximum étant atteinte dans la zone de $\mathrm{pH}$ comprise entre 3,8 et 3,4 .

La figure 5 montre enfin les résultats obtenus lors des macérations de caillettes par la méthode à " $\mathrm{pH}$ constant " en opérant à différents $\mathrm{pH}$.

Pour les macérations faites à $42^{\circ} \mathrm{C}$, l'extraction de la présure et l'activation de la pro-présure sont d'autant plus rapides que le $\mathrm{pH}$ est plus bas (ceci pour la zone de $\mathrm{pH}$ comprise entre 6,0 et 2,5).

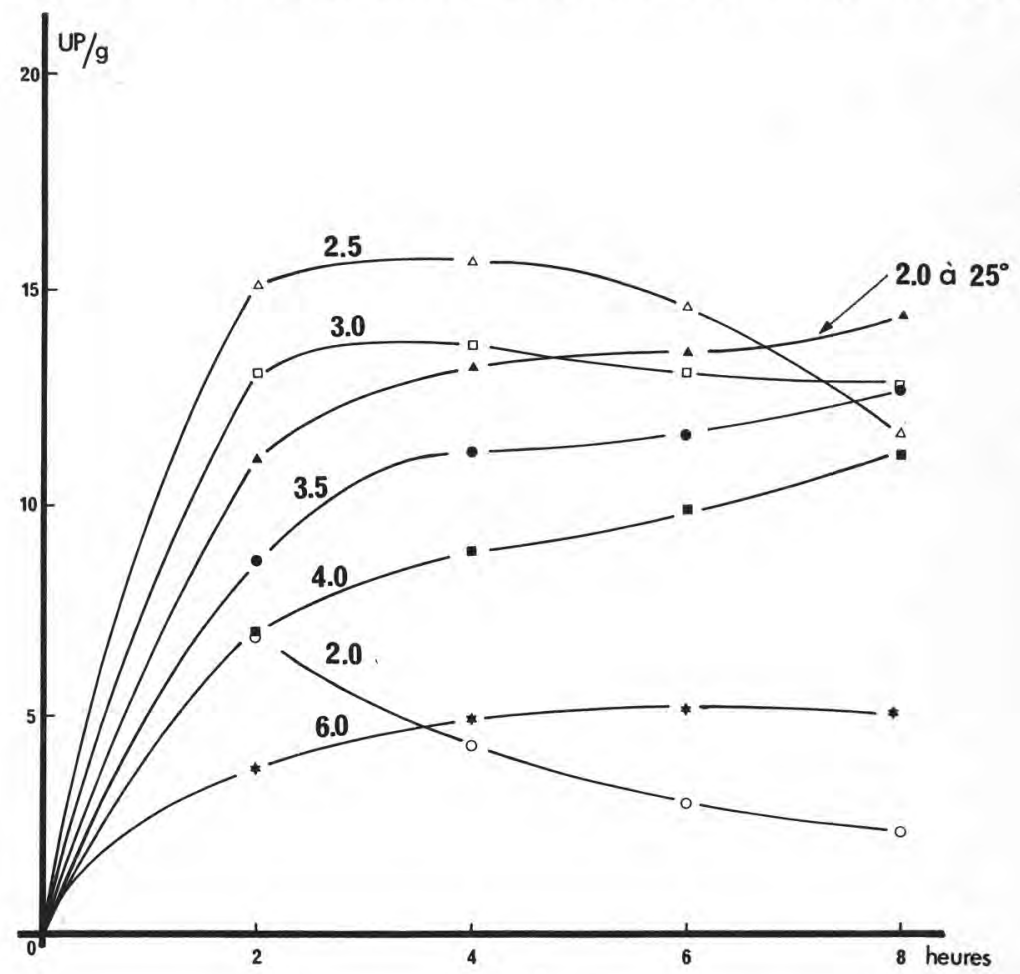

fig. 5

Variation de la concentration en présure en fonction du $\mathrm{pH}$ Méthode « $\mathrm{pH}$ constant »: $15 \mathrm{~g}$ de caillettes +11 de lactosérum acidifié avec l'acide lactique pur.

Température : $42^{\circ} \mathrm{C}$ (sauf pour l'essai à pH 2,0 , effectué à $25^{\circ} \mathrm{C}$ comme indiqué sur la figure).

(macération à $\mathrm{pH} 6,0:+1 \mathrm{ml}$ de toluène). 
A pH 2,0 et à $42^{\circ} \mathrm{C}$ il y a une destruction notable de la présure, tandis qu'à $25^{\circ} \mathrm{C}$ l'extraction et l'activation sont plus lentes, mais il ne semble pas y avoir de destruction de l'enzyme. En outre, au bout de $4 \mathrm{~h}$ de macération à $42^{\circ} \mathrm{C}$, dans la zone de $\mathrm{pH}$ comprise entre 6,0 et 2,5 , la force coagulante est d'autant plus grande que le $\mathrm{pH}$ est plus bas.

\section{2) INFLUENCE DE LA TEMPÉRATURE}

La figure 6 montre les résultats obtenus à $45^{\circ} \mathrm{C}, 42^{\circ} \mathrm{C}$ et $30^{\circ} \mathrm{C}$ avec les macérations traditionnelles. Les températures de $42^{\circ} \mathrm{C}$ ou $45^{\circ} \mathrm{C}$ conduisent à une acidification plus rapide qu'à $30^{\circ} \mathrm{C}$ et l'extraction de la présure est également plus rapide.

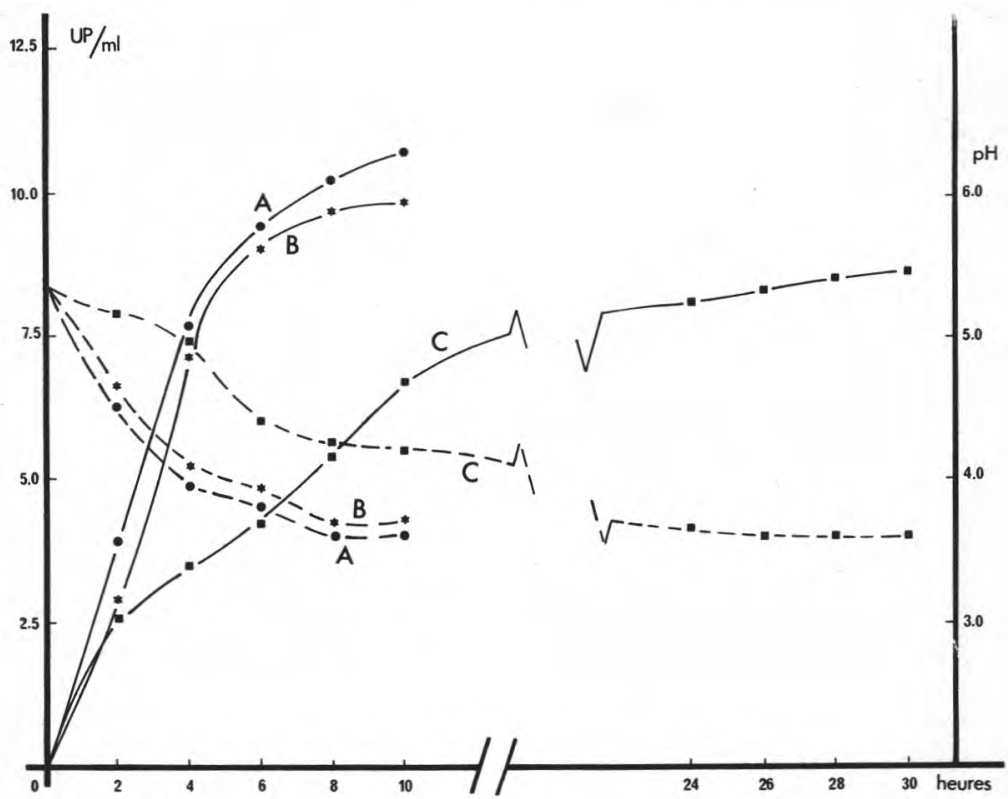

fig. 6

Variation de la concentration en présure en fonction de la température

Méthode "traditionnelle ":

$10 \mathrm{~g}$ de caillettes $+1 \mathrm{l}$ de " recuite ".

$+0,1$ p. 100 de suspension concentrée congelée de $L$. helveticus.

Température :

(A) : $45^{\circ} \mathrm{C}$.

(B) : $42^{\circ} \mathrm{C}$

(C) : $30^{\circ} \mathrm{C}$

$\mathrm{UP} / \mathrm{ml}$

$\mathrm{pH}$. 
La figure 7 montre les résultats correspondant à des macérations à « $\mathrm{pH}$ constant " $(3,5)$ à $15^{\circ} \mathrm{C}, 25^{\circ} \mathrm{C}, 42^{\circ} \mathrm{C}, 50^{\circ} \mathrm{C}, 55^{\circ} \mathrm{C}$ et $60^{\circ} \mathrm{C}$. On voit qu'entre $15^{\circ} \mathrm{C}, 25^{\circ} \mathrm{C}$ et $42^{\circ} \mathrm{C}$, l'extraction est d'autant plus rapide que la température est plus élevée. Lorsqu'on atteint $50^{\circ} \mathrm{C}$, intervient un phénomène de destruction de la présure de sorte qu'on aboutit à un rendement d'extraction plus faible. La température de $42^{\circ} \mathrm{C}$ semble être la plus convenable car elle permet d'obtenir en $6 \mathrm{~h}$ le rendement maximum sans destruction appréciable de la présure.

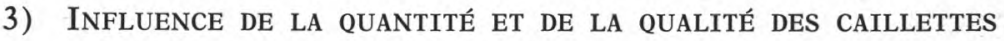

La concentration en présure varie presque proportionnellement au poids de caillettes utilisé par litre de macération (entre 5 et

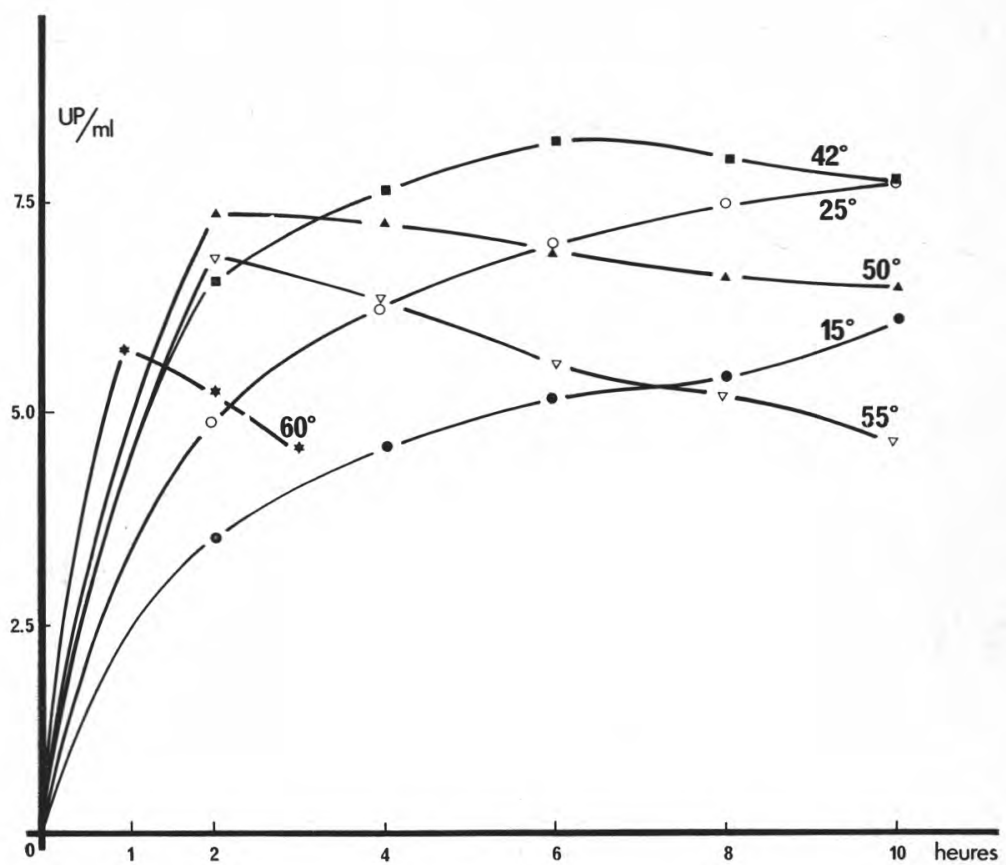

fig. 7

Variation de la concentration en présure en fonction de la température

Méthode à " $\mathrm{pH}$ constant ": $10 \mathrm{~g}$ de caillettes + $1 \mathrm{l}$ de « recuite » acidifiée à $\mathrm{pH} 3,5$. 
$100 \mathrm{~g}$ ) et des variations notables sont observées d'un lot de caillettes à l'autre, comme le montre la figure 8 .

Le rendement d'extraction de la présure - exprimé par le nombre d'unités-présure obtenu par g de caillettes - dépend d'une part de la concentration en présure des macérations, et d'autre part des quantités de présure retenues par les caillettes après macération. Le rendement varie peu pour de faibles poids de caillettes -5 à $10 \mathrm{~g}$ - dans $1 \mathrm{l}$ de milieu de macération mais diminue pour des poids plus élevés $(100 \mathrm{~g})$, comme le montre le tableau 3.

\section{4) INFLUeNCE des Milieux de MacéRATion}

L'extraction de la présure obtenue lors de macérations dans la " recuite » ou dans du lactosérum varie dans l'ensemble relativement peu. Elle est légèrement supérieure dans le cas des macérations " traditionnelles " effectuées dans du lactosérum par compa-

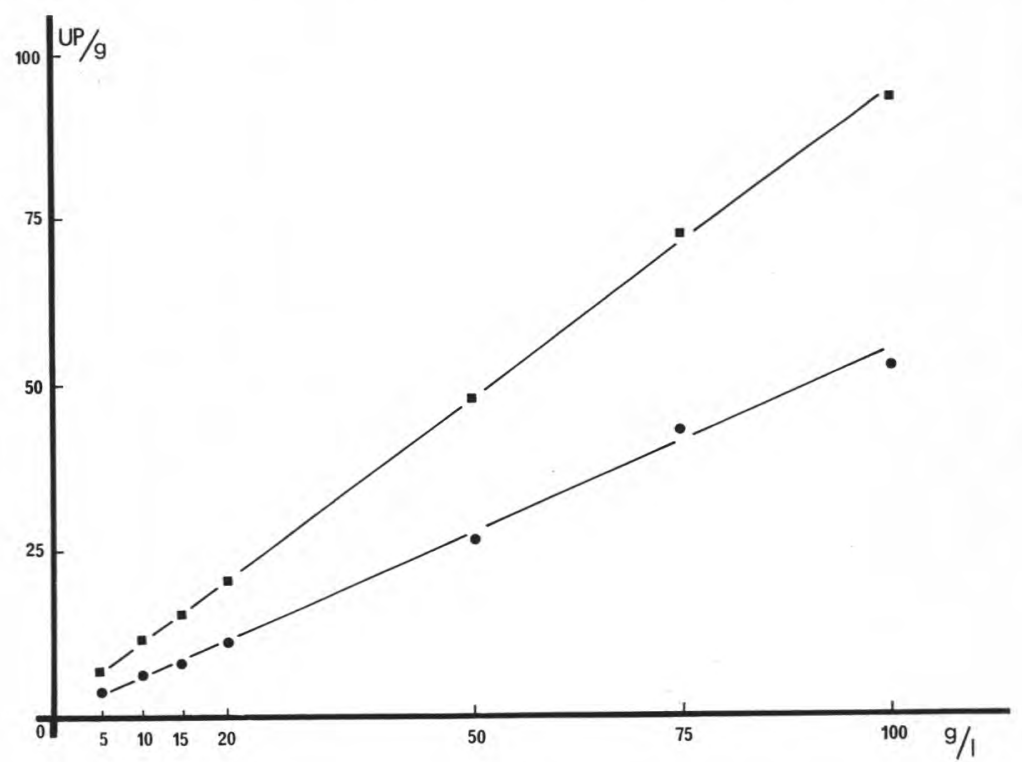

fig. 8

Variation de la concentration en présure.

Influence de la quantité et de la qualité des caillettes

Méthode " traditionnelle ":

$\mathrm{g} / \mathrm{l}$ : poids de caillettes (en g) ajouté à 11 de lactosérum.

$+0,1$ p. 100 de suspension concentrée congelée de L. helveticus.

Température : $42^{\circ} \mathrm{C}$.

Durée de macération : $10 \mathrm{~h}$.

lot de caillettes A.
lot de caillettes B. 
TABLEAU 2. - Préparation de solution de présure à partir de caillettes, selon différentes méthodes

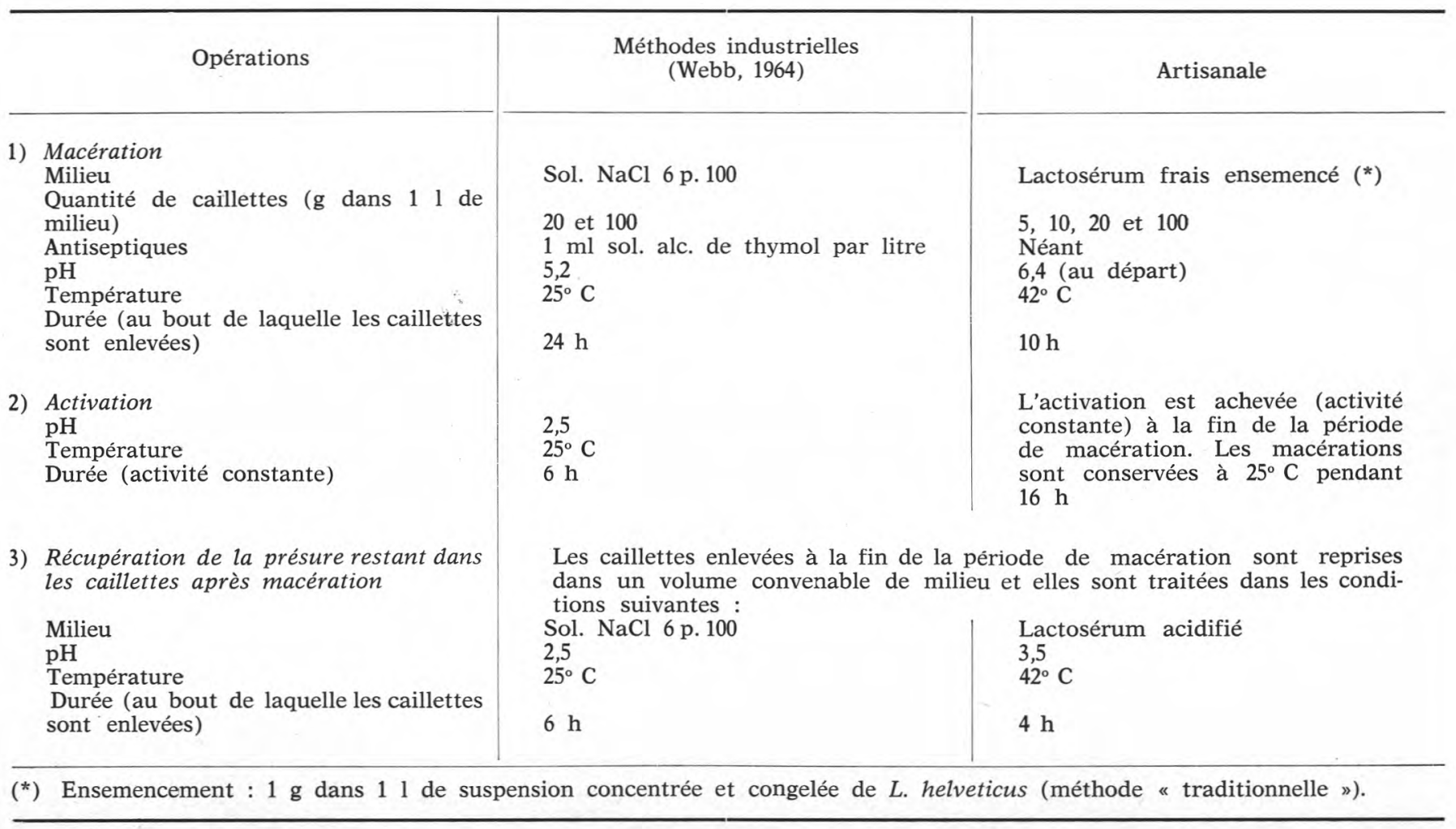


TABLEAU 3. - Préparation de solution de présure à partir de caillettes, selon différentes méthodes

\begin{tabular}{|c|c|c|c|c|c|}
\hline \multirow[t]{2}{*}{ Méthodes } & \multicolumn{3}{|c|}{ Présure obtenue } & \multicolumn{2}{|c|}{ Présure restant dans les caillettes } \\
\hline & $\begin{array}{c}\text { Poids de caillettes } \\
\text { dans } 1 \text { l de milieu } \\
\text { de macération } \\
\text { (en g) }\end{array}$ & $\begin{array}{l}\text { Unités-présure } \\
\text { (totales) }\end{array}$ & $\begin{array}{l}\text { Rendement } \\
\text { d'extraction } \\
\left({ }^{*}\right)\end{array}$ & $\begin{array}{c}\text { Unités-présure } \\
\text { (totales) }\end{array}$ & $\begin{array}{c}\text { Pertes } \\
(* *) \\
\text { (en p. 100) }\end{array}$ \\
\hline $\begin{array}{l}\text { Industrielle } \\
\text { (Webb, 1964) }\end{array}$ & $\begin{array}{r}100 \\
20\end{array}$ & $\begin{array}{l}58600 \\
14200\end{array}$ & $\begin{array}{l}586 \\
710\end{array}$ & $\begin{array}{r}5242 \\
592\end{array}$ & $\begin{array}{l}8,9 \\
4,1\end{array}$ \\
\hline Artisanale & $\begin{array}{r}100 \\
20 \\
10 \\
5\end{array}$ & $\begin{array}{r}53000 \\
14100 \\
7900 \\
4200\end{array}$ & $\begin{array}{l}530 \\
705 \\
790 \\
840\end{array}$ & $\begin{array}{r}15200 \\
1490 \\
503 \\
220\end{array}$ & $\begin{array}{r}28,6 \\
10,5 \\
6,3 \\
5,2\end{array}$ \\
\hline
\end{tabular}

(*) Exprimé en nombre d'unités-présure par g de caillettes.

(**) Calculées en fonction du nombre d'unités-présure totales restant dans les caillettes après macération, par rapport au nombre d'unités-présure totales de la présure obtenue. 
raison avec celles effectuées dans la recuite. Dans le cas des macérations à « pH constant », l'influence de l'un ou l'autre des milieux de macération est pratiquement négligeable (fig. 9).

5) CoMparaison entre difFÉRENTES MÉTHOdeS DE PRÉPARATION DE LA PRÉSURE.

En partant d'un même lot de caillettes nous avons préparé de la présure liquide non clarifiée, selon le procédé habituellement

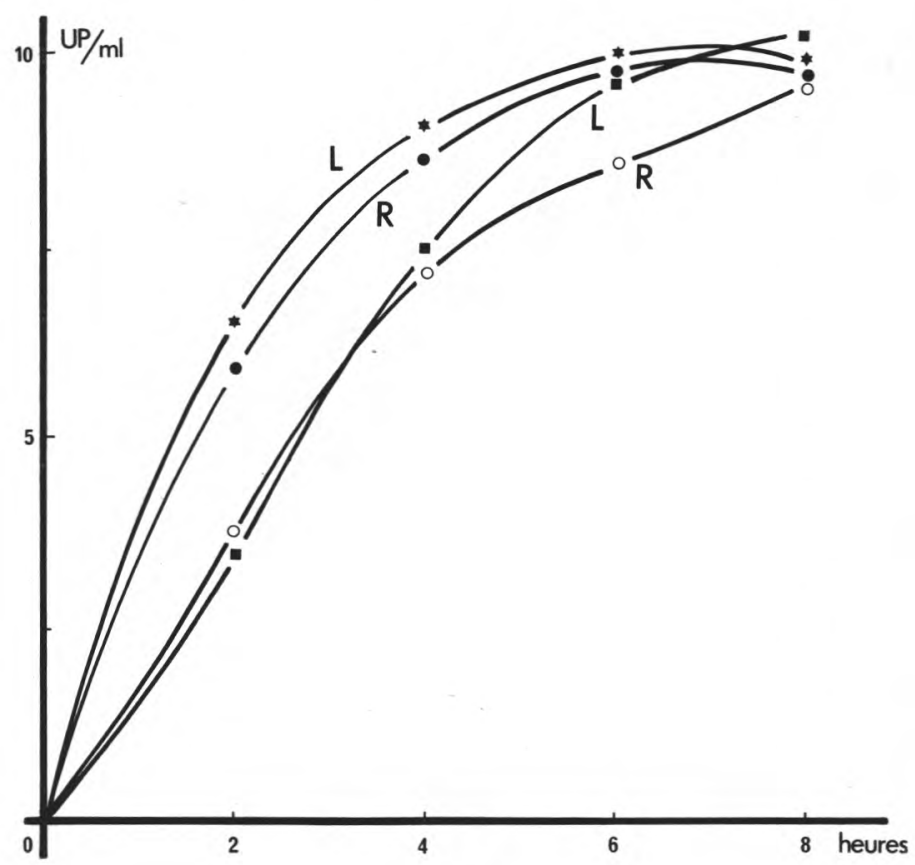

fig. 9

Variation de la concentration en présure. Influence des milieux de macération

Milieu de macération :

$\mathrm{R}$ : " recuite".

L : lactosérum.

Méthode à « $\mathrm{pH}$ constant »: $10 \mathrm{~g}$ de caillettes : + $1 \mathrm{l}$ de milieu de macération acidifié à $\mathrm{pH} 3,5$. Température $42^{\circ} \mathrm{C}$.

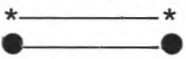

Méthode " traditionnelle »: $10 \mathrm{~g}$ de caillettes $+11 \mathrm{de}$ milieu de macération $+0,1$ p. 100 suspension concentrée congelée de L. helveticus. Température $42^{\circ} \mathrm{C}$.

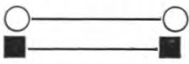


TABLEAU 4. - Conservation de présures artisanales (Température : entre 3 et $5^{\circ} \mathrm{C}$ et à $-30^{\circ} \mathrm{C}$ )

\begin{tabular}{|c|c|c|c|c|c|c|c|c|c|}
\hline \multirow{2}{*}{ Type de présure } & \multirow{2}{*}{$\begin{array}{l}\mathrm{UP} / \mathrm{ml} \\
\text { initial }\end{array}$} & \multicolumn{8}{|c|}{ Pertes d'activité $\left({ }^{*}\right)$ observées au cours d'une période de conservation de : } \\
\hline & & 3 à $5^{\circ} \mathrm{C}$ & $-30^{\circ} \mathrm{C}$ & 3 à $5^{\circ} \mathrm{C}$ & $-30^{\circ} \mathrm{C}$ & 3 à $5^{\circ} \mathrm{C}$ & $-30^{\circ} \mathrm{C}$ & 3 à $5^{\circ} \mathrm{C}$ & $-30^{\circ} \mathrm{C}$ \\
\hline Artisanales & $\begin{array}{r}46,6 \\
38,1 \\
10,9 \\
7,5 \\
6,9 \\
5,1 \\
5,1\end{array}$ & $\begin{array}{l}1,1 \\
0,0 \\
2,0 \\
- \\
- \\
0,0 \\
4,5\end{array}$ & $\begin{array}{l}0,0 \\
0,0 \\
0,0 \\
- \\
\overline{0,0} \\
2,5\end{array}$ & $\begin{array}{l}5,8 \\
0,0 \\
1,9 \\
0,0 \\
6,9 \\
0,0 \\
4,1\end{array}$ & $\begin{array}{l}0,0 \\
0,0 \\
0,0 \\
0,0 \\
0,0 \\
0,0 \\
2,5\end{array}$ & $\begin{array}{r}13,0 \\
5,5 \\
11,0 \\
1,5 \\
6,8 \\
3,3 \\
6,9\end{array}$ & $\begin{array}{l}0,0 \\
0,0 \\
0,0 \\
0,0 \\
2,7 \\
0,0 \\
2,5\end{array}$ & $\begin{array}{r}16,0 \\
9,4 \\
16,9 \\
7,0 \\
7,3 \\
7,3 \\
8,8\end{array}$ & $\begin{array}{l}0,0 \\
0,0 \\
0,0 \\
0,0 \\
2,4 \\
0,0 \\
2,5\end{array}$ \\
\hline $\begin{array}{l}\text { Méthode de Foltmann }\left(^{* *}\right) \\
\text { pH } 3,5 \\
\text { pH } 5,6\end{array}$ & $\begin{array}{l}33,2 \\
33,2\end{array}$ & $\begin{array}{r}16,0 \\
0,0\end{array}$ & $\begin{array}{l}0,0 \\
0,0\end{array}$ & $\begin{array}{r}33,0 \\
0,0\end{array}$ & $\begin{array}{l}0,0 \\
0,0\end{array}$ & $\begin{array}{r}43,6 \\
0,0\end{array}$ & $\begin{array}{l}1,0 \\
0,0\end{array}$ & $\begin{array}{r}48,0 \\
0,0\end{array}$ & $\begin{array}{l}3,0 \\
0,0\end{array}$ \\
\hline
\end{tabular}

(*) Perte d'activité exprimée en p. 100 de l'activité initiale.

(**) Présure liquide clarifiée obtenue suivant la technique de Foltmann : pH 3,5 ajusté avec de l'acide lactique. Le pH 5,6 est celui recommandé par l'auteur pour la conservation de la présure. 
utilisé dans l'industrie (macération des caillettes dans une solution de $\mathrm{NaCl}$ (Webb [18]) et selon la méthode "traditionnelle » de préparation des présures artisanales. Le tableau 2 montre l'essentiel des opérations suivies et le tableau 3 rend compte des résultats obtenus.

\section{6) CONSERVATION DES PRÉSURES aRTiSANALES}

On a étudié la conservation des présures artisanales dans les conditions décrites. On a étudié, d'une part les conservations de présures préparées selon la méthode "traditionnelle " lors de la macération à $42^{\circ} \mathrm{C}$ pendant 8 à $10 \mathrm{~h}$. Dans la pratique courante, ces présures sont conservées à température ambiante (entre 20 à $25^{\circ} \mathrm{C}$ ) pendant 12 à $14 \mathrm{~h}$, avant leur emploi. On a constaté que pendant cette période les pertes d'activité étaient négligeables. Par ailleurs, on a étudié la conservation des présures artisanales aux températures comprises entre $3^{\circ} \mathrm{C}$ et $5^{\circ} \mathrm{C}$ et entre $-28^{\circ} \mathrm{C}$ et $-30^{\circ} \mathrm{C}$. On a également étudié le comportement d'une présure obtenue selon le procédé de Foltmann [19], ajustée à $\mathrm{pH}$ 3,5 avec l'acide lactique pur et conservée aux mêmes températures. L'ensemble des résultats présentés dans le tableau 4 montre qu'entre $3^{\circ} \mathrm{C}$ et $5^{\circ} \mathrm{C}$ les présures artisanales, dont le $\mathrm{pH}$ est compris entre 3,4 et 3,8 , se conservent mieux que la présure obtenue par macération des caillettes dans une solution de $\mathrm{NaCl}$ dans la même zone de $\mathrm{pH}$. En effet, au bout de $30 \mathrm{j}$ de conservation, les présures artisanales perdent entre 7 et 16 p. 100 de leur activité originale, tandis que la présure extraite dans une solution de $\mathrm{NaCl}$ perd au cours de la même période 48 p. 100 de son activité. A une température comprise entre $-28^{\circ} \mathrm{C}$ et $-30^{\circ} \mathrm{C}$, les pertes se situent dans les deux cas autour de 3 p. 100 seulement.

Les présures lyophilisées, conservées pendant 9 mois entre $3^{\circ} \mathrm{C}$ et $5^{\circ} \mathrm{C}$, ont montré des pertes d'activité comprises entre 0 et 14 p. 100 , comme le montre le tableau 5 .

\section{TABLEAU 5}

Présures lyophilisées après 9 mois de conservation au réfrigérateur à $3-5^{\circ} \mathrm{C}$

\begin{tabular}{c|c}
\hline $\begin{array}{c}\text { Activité initiale } \\
\text { (en U.P. par g) }\end{array}$ & $\begin{array}{c}\text { Pertes } \\
\text { d'activité }{ }^{*} \text { ) }\end{array}$ \\
\hline & \\
44,0 & 14,0 \\
68,0 & 3,0 \\
91,0 & 0,0 \\
121,0 & 3,0 \\
210,0 & 11,0 \\
\hline
\end{tabular}

(*) Exprimées en p. 100 de l'activité initiale. 


\section{DISCUSSION}

Les résultats obtenus concordent, en ce qui concerne l'obtention de la présure dans les macérations traditionnelles, avec ceux de Mc Clintock (1950). Ils sont d'autre part en accord avec l'ensemble des observations de Foltmann [19] au sujet de l'activation de la proprésure en fonction du $\mathrm{pH}$. On constate qu'au-dessous de $\mathrm{pH} 5,0$ l'obtention de la présure dans les macérations est, pour une température donnée, d'autant plus rapide que le $\mathrm{pH}$ est plus bas jusqu'à 3,8-3,4 pour les macérations traditionnelles et $3,0-2,5$ pour les macérations à « $\mathrm{pH}$ constant ».

La stabilité de la présure dans les macérations à $\mathrm{pH}$ compris entre 3,4 et 3,8 semble être plus grande que celle observée par Rand et Ernstrom [20] sur des solutions de présure dans des tampons à $\mathrm{pH} 3,4$ et 4,0 . Nous avons nous-mêmes vérifié ce manque de stabilité d'une solution saline de présure à $\mathrm{pH}$ compris entre 3,4 et 3,8 pendant la conservation entre $3^{\circ} \mathrm{C}$ et $5^{\circ} \mathrm{C}$. Le milieu de macération exerce probablement dans cette zone de $\mathrm{pH}$ un effet protecteur se traduisant par cette meilleure stabilité des présures artisanales.

La méthode " traditionnelle " de préparation des présures artisanales permet l'obtention de rendements d'extraction pratiquement du même ordre que ceux obtenus par le procédé industriel de préparation de la présure basé sur la macération des caillettes dans des solutions de $\mathrm{NaCl}$. D'autre part, les quantités de présure retenues par les caillettes conduisent à des pertes de présure assez faibles : de 5 à $10 \mathrm{p}$. 100 pour des poids de caillettes variant entre 5 et $20 \mathrm{~g}$ par litre de milieu de macération. Ces poids correspondent d'ailleurs aux quantités de caillettes couramment employées en fromagerie pour la préparation de présures artisanales.

La méthode artisanale de préparation de la présure, si elle est bien conduite, ne comporte donc aucun gaspillage de caillettes.

Par ailleurs, 1'application de la méthode artisanale à des poids de caillettes de l'ordre de $100 \mathrm{~g}$ par litre de milieu de macération conduit à des rendements d'extraction de la présure inférieurs de 20 p. 100 à ceux obtenus avec la méthode industrielle. De ce fait la préparation de présure artisanale concentrée ne semble possible que si l'on récupère la présure retenue par les caillettes.

La préparation artisanale de la présure utilisée dans les fromages de Gruyère de Comté et d'Emmental repose sur l'abaissement du $\mathrm{pH}$ des milieux dans lesquels sont effectuées les macérations. Les rendements en présure étant fonction de la fermentation lactique, il est primordial de bien régler l'acidification au cours des macérations. Une acidification permettant d'atteindre la zone de $\mathrm{pH}$ comprise entre 3,8 et 3,4 au bout de 6 à $10 \mathrm{~h}$ à $42^{\circ} \mathrm{C}$ assure des conditions satisfaisantes d'extraction et d'activation. Ce même résultat peut être obtenu à $30^{\circ} \mathrm{C}$ après 24 à $28 \mathrm{~h}$ de macération. 
Pour une température et une durée de macération données, tous les facteurs susceptibles de retarder l'acidification entraînent une diminution des rendements d'extraction de la présure. Le procédé, assez répandu en pratique, qui consiste à faire les macérations sans autre apport de bactéries lactiques thermophiles que celles qui peuvent provenir des caillettes elles-mêmes risque donc de conduire à des résultats incertains.

L'ensemencement des macérations avec des cultures de bactéries lactiques thermophiles est donc essentiel.

L'utilisation d'autres températures (entre $25^{\circ} \mathrm{C}$ et $45^{\circ} \mathrm{C}$ ) que celles de $30^{\circ} \mathrm{C}$ et $42^{\circ} \mathrm{C}$ permet d'obtenir les mêmes résultats du point de vue rendement d'extraction de la présure. Dans le cas des macérations "traditionnelles », la température de $42^{\circ} \mathrm{C}$ doit être préférée à celle de $30^{\circ} \mathrm{C}$. D'une part l'obtention de la présure est pratiquement terminée au bout de 6 à $10 \mathrm{~h}$ au lieu de $24-28 \mathrm{~h}$; d'autre part la température de $42^{\circ} \mathrm{C}$ convient mieux au développement des bactéries lactiques thermophiles nécessaires à l'acidification des fromages sous presse.

La stabilité de la présure dans les macérations effectuées dans la zone de $\mathrm{pH} 3,8-3,4$ aux températures comprises entre $3^{\circ} \mathrm{C}$ et $5^{\circ} \mathrm{C}$ et entre $-28^{\circ} \mathrm{C}$ et $-30^{\circ} \mathrm{C}$ permet de conserver les présures artisanales sans leur faire subir aucun traitement comportant l'addition d'antiseptiques. On pourrait donc songer à la préparation de telles présures en dehors de la fromagerie, pour les fabrications de Comté et d'Emmental. Cette possibilité doit être envisagée à condition de disposer de cultures de bactéries lactiques " ad hoc ». Les présures artisanales concentrées, conservées congelées, pourraient être utilisées, par exemple, avec des suspensions concentrées et congelées de bactéries lactiques thermophiles [16]. L'emploi de présures artisanales lyophilisées serait également un procédé de choix à envisager.

\section{R é s u m é}

Les différentes conditions d'obtention de la présure au moyen d'une macération de caillettes sèches dans le lactosérum ou la " recuite » ont été étudiées : la concentration en présure obtenue varie en fonction du $\mathrm{pH}$, de la température, de la durée des macérations, de la quantité et de la qualité des caillettes.

Pour des poids de caillettes de 5 à $20 \mathrm{~g}$ par litre, le procédé de préparation artisanal permet d'obtenir des rendements d'extraction de la présure comparables à ceux obtenus, avec ces mêmes poids, par macération des caillettes dans une solution de chlorure de sodium.

Il est possible de conserver les présures artisanales sous forme congelée à $-30^{\circ} \mathrm{C}$ pendant 1 mois ou sous forme lyophilisée pendant 9 mois pratiquement sans perte d'activité. Les macérations 
dont le pH est compris entre 3,8 et 3,4 se conservent de façon encore satisfaisante pendant environ 1 mois, sans addition d'antiseptiques, lorsqu'elles sont maintenues entre $3^{\circ} \mathrm{C}$ et $5^{\circ} \mathrm{C}$.

\section{S u $\mathbf{m} \mathbf{m}$ a r y}

A study of traditionnal method for preparing rennet used in Gruyère de Comté and Emmental cheese

The different conditions which must be fulfilled in order to obtain good preparations of rennet from caves dried vells macerated in whey or in whey without albumin ( recuite»), as used in the manufacture of Gruyère de Comté and Emmental cheese have been studied.

The concentration of rennet obtained is a function of $\mathrm{pH}$, temperature and time of extraction as well as of the amount and quality of the vells used.

The traditionnal procedure for preparing rennet for Gruyère de Comté and Emmental cheese, using from 5 to $20 \mathrm{~g}$ of vells per litre, gives a yield about equal to the yield obtained with a maceration of the same weigth of vells in brine.

It is possible without noticeable lowering of the activity, to keep the "traditionnal rennets " either by freeze-drying and storage at $5^{\circ} \mathrm{C}$, or storing without freeze-drying at $-30^{\circ} \mathrm{C}$. Furthermore, preparations at $\mathrm{pH}$ 3.8-3.4 are stable without addition of preservatives for about 1 month at 3 to $5^{\circ} \mathrm{C}$.

\section{Remerciements}

Nous remercions vivement $M$. Vassal pour les suggestions et les conseils qu'il nous a apportés au cours de ce travail et la rédaction du manuscrit. Nous remercions également $M$. Uro qui a bien voulu lyophiliser les différentes préparations de présure.

Reçu pour publication en mars 1972.

\section{Bibliographie}

[1] KaRnicki (F.) von, DoRner (W.) (1934). - Die Milchsäurebakterien flora der in der schweizerischen Käserei üblichsten Lab und Kulturarten. Landw. Jahrb. Schweiz., 58, 715-801.

[2] Mosimann (W.) (1944). - Die bakterielle Besiedling frischer und getrockneter Kälberlabmägen mit besonderer Berücksichtigung der thermophilen Säuerungsflora. Landw. Jahrb. Schweiz., 58, 715-801.

[3] Burri (R.) von, Kollmann (H.) (1941). - Studien über Gattung Thermobacterium (Orla-Jensen) mit besoderer Berücksichtigung der Säuerungsflora des jungen Emmentalerkäse. Landw. Jahrb. Schweiz, 55, 407-430.

[4] BurRt (R.) von, Elser (E.) (1941). - Zur Kenntnis der im Emmentalerkäse auftretenden Streptokokken. Landw. Jahrb. Schweiz., 55, 176-193. 
[5] Accolas (J. P.) Auclair (J.) (1964). - Etude bactériologique des levains utilisés dans la fabrication du Gruyère. Ann. Technol. Agric., 13 (2), 85-96.

[6] Frazier (W. C.), Sanders (G. P.), Boyer (A. J.), Long (H. F.) (1934). - The bacteriology of swiss cheese. I. Growth and activity of bacteria during manufacturing processes in the Swiss cheese kettle. J. Bacteriol., 339-349.

[7] Frazier (W. C.), Burkey (A. L.), Boyer (A. J.), Sanders (G. P.), Matheson (K. J.) (1935). - The bacteriology of Swiss cheese. II. Bacteriology of the cheese in the press. J. Bacteriol., 18, 373-387.

[8] Frazier (W. C.), Johnson (W. T.) Jr., Evans (F. R.) and Ramsdell (G. A.) (1935). - The bacteriology of Swiss cheese to quality cheese. J. Dairy Sci., $18,503-510$.

[9] Burkey (L. A.) Sanders (G. P.) Matheson (K. J.) (1935). - The bacteriology of Swiss cheese. IV. The effect of temperature upon bacterial activity and drainage in the press. J. Dairy Sci., 18, 719-731.

[10] Peter (A.), Zollikofer (E.), Badoux (F.) (1944). - Manuel de la fabrication du fromage d'Emmental. Edition des Hoirs C.J. Wyss S.A., Berne.

[11] Dorner (W.), Demont (P.), Chavannes (D.) (1945). - Microbiologie laitière. Librairie Payot, Lausanne.

[12] KuRsteineR (J.), Staud (W.) (1950). - Merkbläter für den Emmentalerkäser. Bern : Schweiz. Käse-Union AG und Schweiz. Milchwirtschaftlicher Vereines.

[13] OrLa-Jensen (S.) (1907). - Note sur la présure et sa préparation. Rev. Gén. Lait., 6, 272-281.

[14] KoestLer (G.) (1939). - Einflus verschiedener Labaiten auf die Teigbeschaffenneit des Emmentalerkäse. Schweiz Milchztg., 65, (81), 419.

[15] Koestler (G.) (1942). - Notiz über den Eiweissbau in dem verschiedenen Labsorten hergestellen Emmentalerkäse. Schweiz. Milchztg., 68, (72), 323.

[16] Valles (E.), Mocouot (G.) (1968). - Préparation de suspensions concentrées et congelées de bactéries lactiques thermophiles destinées à la fromagerie. Le Lait, 48, 631-643.

[17] Berridge (N. J.) (1955). - Purification and Assay of Rennin. Methods in Enzymology, vol. II 69-77. SP Colowick and N. J. Kaplan, eds. Academic Press, New-York.

[18] WeBB (F. C.) (1964). - Commercial enzymes. Biochemical engineering, 519612. Van Nostrand. Princeton, New-Jersey. Cité par REED (G.) and UNDERKOFLer (L.) (1966). - Enzymes in Food Processing. 202. Academic Press., New-York and London.

[19] Foltmann (B.) (1966). - A review on pro-rennin and rennin. C.R. trav. Lab. Carlsberg, 3 (8), 145-221.

[20] Rand (A. C.), ERnstrom (C. A.) (1964). - Effect of pH and sodium chloride on activation of pro-rennin. J. Dairy Sci., 47, 1181-1187. 